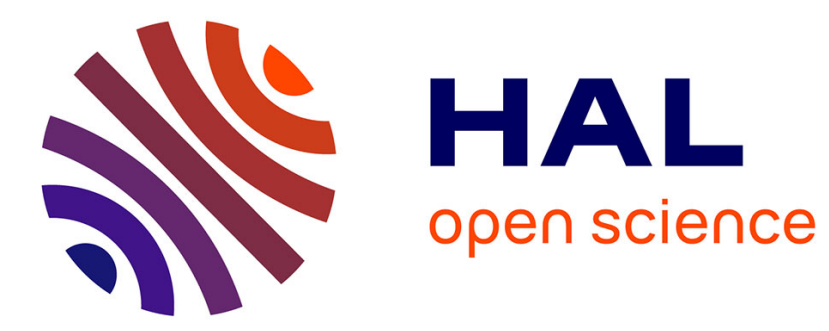

\title{
Proposal of an Erasure-Oriented Drawing Style to Develop the Ability to Copy Images
}

\author{
Riho Kurotaki, Yoshinari Takegawa, Keiji Hirata
}

\section{To cite this version:}

Riho Kurotaki, Yoshinari Takegawa, Keiji Hirata. Proposal of an Erasure-Oriented Drawing Style to Develop the Ability to Copy Images. 16th International Conference on Entertainment Computing (ICEC), Sep 2017, Tsukuba City, Japan. pp.233-239, 10.1007/978-3-319-66715-7_26 . hal-01771245

\section{HAL Id: hal-01771245 \\ https://hal.inria.fr/hal-01771245}

Submitted on 19 Apr 2018

HAL is a multi-disciplinary open access archive for the deposit and dissemination of scientific research documents, whether they are published or not. The documents may come from teaching and research institutions in France or abroad, or from public or private research centers.
L'archive ouverte pluridisciplinaire HAL, est destinée au dépôt et à la diffusion de documents scientifiques de niveau recherche, publiés ou non, émanant des établissements d'enseignement et de recherche français ou étrangers, des laboratoires publics ou privés. 


\title{
Proposal of an Erasure-Oriented Drawing Style to Develop the Ability to Copy Images
}

\author{
Riho Kurotaki $^{1 \star}$, Yoshinari Takegawa ${ }^{1}$, and Keiji Hirata ${ }^{1}$ \\ ${ }^{1}$ Future University Hakodate, Hakodate, Hokkaido, Japan \\ \{g2117019, yoshi, hirata\}@fun.ac.jp \\ http://hiratakelab.jp/
}

\begin{abstract}
The purpose of this study is the proposal of an erasureoriented drawing style to develop the ability to copy images. Possible erasable parts of an existing illustration were inferred and classified. As a result, the erasure processes were divided into two types and regarded as erasure patterns in this study. Then, we created an illustration drawing support system that makes use of erasure method. By automatically performing part of erasure, we made the drawing and erasure processes of illustration easier to memorize. Also, using drawing songs as models, we supported memorization of the procedures from auditory sense.
\end{abstract}

Keywords: Illustration $\cdot$ Drawing $\cdot$ Character $\cdot$ Drawing song

\section{Introduction}

There are various kind of picture, such as portraits, but we focus on pictures (illustrations) that are simplified versions of real things, like the image in Figure 1. Illustrations are easier to convey than sentences when used to explain to others. For example, when making ideas with multiple people such as meeting, it becomes easier to concretely image by drawing illustrations. As a result, people will be able to smoothly progress discussions, so the skills to draw illustrations is important.

Copying is the basic practice for developing illustration drawing skills. In general, there are many ways to copy from a model image, but it takes time to develop skills, or monotonous repetition is necessary. Also, copying generally involves the drawing of auxiliary lines and guidelines to determine the composition and position of parts.

In this study, we adopt the approach that by assertively utilizing and increasing editing ability, we can also increase the ability to imitate an example image. As the first step, we focus on the editing operation of erasure. For example, the shape in Figure 2 is an unfamiliar shape, unlike a circle or a rectangle. To draw this using an erasure method, two ellipses are aligned and the dotted line is erased, as shown in Figure 3. Although it is difficult to accurately imitate

\footnotetext{
* Dept. of Systems Information Science, Future University Hakodate, Hakodate, Hokkaido 041-8655, Japan
} 
unfamiliar figures in this way, by assertively introducing the erasure method, the threshold of the required drawing skill is lowered.

Therefore, we aim to propose an erasure-oriented drawing style to develop the ability to imitate model images.

The distinctive feature of this research is the drawing of illustrations on the premise of erasing. The proposed system has a function that automates a part of the erasure method to enable users to erase efficiently, a function that enables users to self-analyze the similarity between the model and their own illustrations, and a model, in the form of drawing song, to enable efficient memorization of drawing and erasing procedures. Through this study, we help people who are not good at drawing shapes and have a weak consciousness to draw shapes according to model.

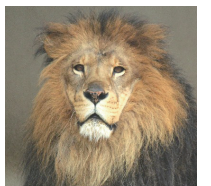

Motif

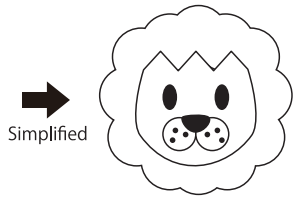

Illustration

Fig. 1. Relationship between motif and illustration in this study

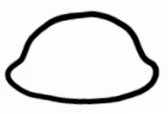

Fig. 2. Existing illustration

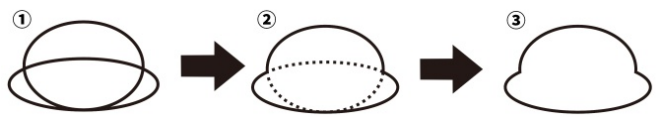

Fig. 3. Draw Figure 2 using editing operation

\section{Related Work}

Murakami et al. [1] created a learning system for self-taught drawing of characters. An illustration drawn by the user is processed into evaluation images. After that, it is evaluated from three viewpoints and a score is given as feedback. However, when the evaluation result is low, this system does not show which parts should be modified. For example, if the evaluation is low when the centers of the evaluation image and the model are aligned, it is possible for the user to infer that the size and overall balance are bad. However, it is difficult to achieve deep understanding, because it is only the user's consideration.

\section{Erasure Method}

From 44 existing illustrations, we searched for examples where the erasure method works efficiently. As a result of analysis, the erasure processes were divided into two types. These two types were regarded as erasure patterns in this study. The details are as follows:

(1) Erasing all the lines of one diagram

Diagrams are used as auxiliary lines, and the completed illustration does 
not include the initial diagrams. In Figure 4, a circle and lines in the form of an asterisk are drawn. These diagrams are overlapped, then the intersections are connected to form a hexagon. Finally, the original circle and lines are erased.

(2) Erasing partially the lines of one diagram

Part of the initial diagram is erased, while other parts are left. This method can be divided into three patterns:

(a) Erasing a single line of a diagram

In Figure 5, an overlapped circle and rectangle are drawn. Then, only the line of the circle that overlaps the rectangle is erased.

(b) Erasing multiple lines of diagrams

In Figure 6, a circle and rectangle are drawn, as in (a). Then, the lines of the circle and rectangle that are contained within the main outline are erased, to create a single shape.

(c) Erasing overlapping edges

In Figure 7, two identical rectangles are prepared, and placed such that one side of each rectangle partially touches the other. Then, this adjoining line is erased.
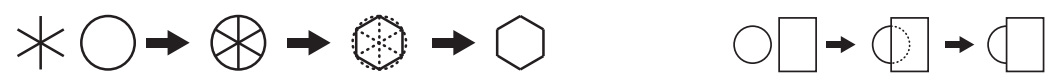

Fig. 4. Erasing all the lines of a diagram

Fig. 5. Erasing a single line of a diagram

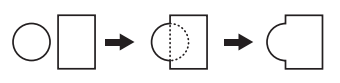

Fig. 6. Erasing multiple lines of diagrams

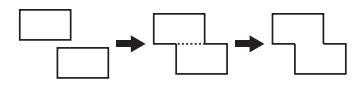

Fig. 7. Erasing overlapping edges

\section{Proposed System}

\subsection{System Requirements}

Automation of Part of Erasure : The proposed method of adding erasure increases the processes involved when compared to existing drawing styles of simply drawing by adding more and more lines. In addition, the importance of learning in each process is different. For example, what the user should learn in erasing is the procedure of what part to erase with what timing. Therefore, the memory of the procedure has high importance. In contrast, the erasure of unnecessary lines by the user is simple and easy to learn, so it has low importance. As described earlier, it is necessary to separate the processes into two types: manual operations performed by the user, and automatic operations performed by the system.

Drawing Songs as Models : The metaphors of drawing songs are used to enable users to remember how to draw accurately in a short time. Drawing 
songs are one kind of Japanese play song, by which shapes, like that shown in Figure 8, are drawn by following the lyrics, as shown in Table 1. By the end of the song the illustration is complete. The characteristic of drawing songs is to draw while listening to a song. Ron [2] cited the advantages of a memorization method using parody songs, stating that when recalling part of the rhythm and lyrics, one also recalls the thing related to them. In these parody songs, the lyrics are about the thing one wants to memorize, so the same effect can also be expected from drawing songs. In addition, Kinoshita et al. [3] have confirmed that the creation of drawing songs is effective in reducing awareness of one's lack of confidence regarding drawing and music. It is said that this is caused by experiencing returning to a childlike mentality and drawing, and singing a song, and we expected that the same effect would be obtained in our study as well.

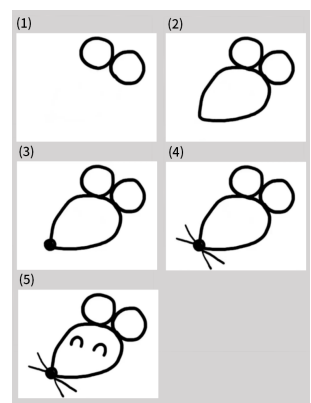

Table 1. Lyrics

\begin{tabular}{|l|l|}
\hline$(1)$ & After all it is two a dumpling \\
\hline$(2)$ & smartly I put one strawberry \\
\hline$(3)$ & I put only one bean \\
\hline$(4)$ & A lot of buds appear once again \\
\hline$(5)$ & squeaky It's a mouse \\
\hline
\end{tabular}

Fig. 8. An existing drawing song [4]

Using the Advantages of Existing Drawing Learning : One existing drawing learning methods is to attend drawing classes. This has the advantage that the learner can receive advice from the teacher on the spot. We aim to introduce this advantage into the proposed system.

\subsection{Presented Contents}

Figure 9 shows the proposed system ${ }^{1}$. It is supposed to be used on a tablet PC. Because it is easy to carry, the users can learn regardless of location and time. By using a touch pen, it is like drawing with analog tools. Details of the contents are given below. The numbering corresponds to the numbers in Figure 9 .

\section{(1) Model movie area}

Plays the model movie selected using (3). Operated with button group (4).

\section{(2) Drawing area}

To draw and erase.

(3) Model select button

Selects the model movie to be displayed in (1). INTRO is an explanation of the erasure method in this system. START is the drawing song.

\footnotetext{
$\overline{1}$ https://goo.gl/sXxdwc
} 


\section{(4) Model operation button}

Operates model movie.

\section{(5) Drawing support button}

Provides drawing support by switching between drawing mode and erasure mode (Mode) etc. The user touches Mode to switch to erasure mode, and touches the line he/she wants to erase. Then, the system automatically erases that line.

\section{(6) Move to assessment button}

Saves the drawing area as an image, and switches to the assessment page.

\section{(7) Model area}

Shows the model image. Under the model, the ratio between the model and a user's image is displayed. At the time of size assessment, the deviation from the center of the model is displayed.

(8) Assessment area

Shows the assessment result selected with (9).

(9) Assessment select button

From the top: Size superimposes the model image as it is. Face balance, Ear balance, Nose balance, and Eye balance are matched to the contours of face, right ear, nose, and right eye, respectively.
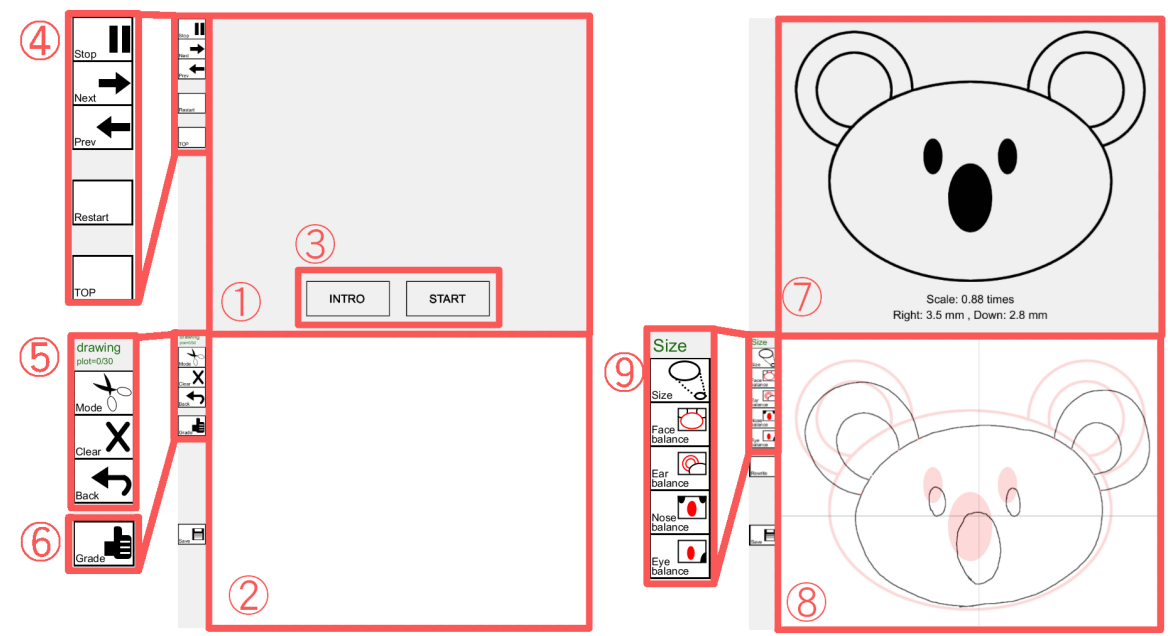

Fig. 9. Proposed system / (left)Top page, (right)Grading page

\subsection{Assessment Function}

In this study, it is important that users notice points for improvement themselves from the information given from the proposed system. Therefore, the assessment page of the proposed system does not show the correct position.

Figure 10 represents the assessment page for each feature. (1) is face, (2) is ear, (3) is nose and (4) is eye. For example, in (1), because the right ear is large 
and the position of the right eye is shifted compared to the model, the balance is bad. However, in (2), the shape of the right ear matches with the model, and the size of the right ear and the position of the eyes and the nose are like the model. As a result, users are able to notice that modifying the outline of the face, rather than the right ear, makes their drawing closer to the model.

(1)
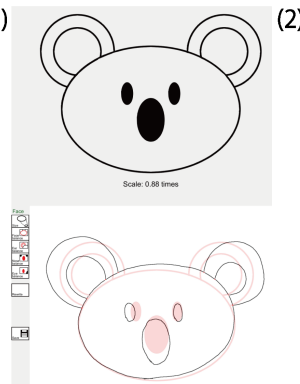
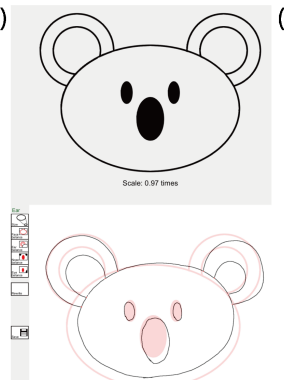

(3)
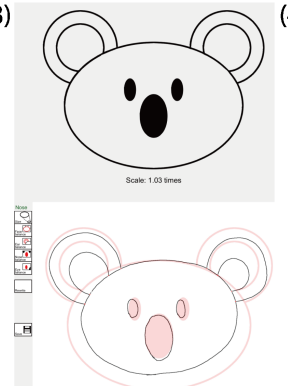

(4)
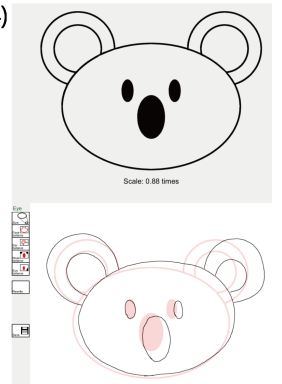

Fig. 10. Proposed system / Each assessment page

\section{Conclusion}

The purpose of this study is the proposal of an erasure-oriented style to develop the ability to copy images. We considered the places where erasure works, from existing illustrations, and established erasure patterns. Also, we created a system that can efficiently erase. By automating a part of the erasure process and using a drawing song as a model, we made it easier to memorize the illustration procedure. In the assessment function, we did not directly present the deviation from the example, but instead superimposed a model to make learners themselves aware of deviations and points for improvement.

Our future task is to increase the number of models. Currently, only one model is available, and even if users become able to draw one model perfectly, it cannot be said that it they have become able to draw illustrations. It is therefore essential also to learn combinations of erasure patterns and illustrations involving the drawing of varying shapes.

\section{References}

1. Ryuichi Murakami, Noriaki Muranaka. "Grading evaluation method in character drawing study support system”. IEEE 45th International Symposium on MultipleValued Logic. 2015. pp. 127-131.

2. Ron Hale-Evans: Mind Performance Hacks: Tips \& Tools for Overclocking Your Brain, O'Reilly Media (2006).

3. Nobuyoshi Kinoshita, Osamu Nishida. "A study on the creation of drawing songs -Practice examples in teacher training agencies-”. Educational Practice Center. 2009. pp. 147-158.

4. Drawing Song of animals, “Drawing Song of animals”. https://youtu.be/ j8ZXHw1aKG0. (2016/9/20 Accessed) 